\title{
Response to corticosteroid therapy is not related to serum and urine NGAL concentration in nephrotic children
}

\author{
Agnieszka Ochocińska1', Wioletta Jarmużek², Roman Janas', Ryszard Grenda² \\ 'Department of Biochemistry, Radioimmunology, and Experimental Medicine, The Children's Memorial Health Institute, \\ Warsaw, Poland \\ ${ }^{2}$ Department of Nephrology, Kidney Transplantation, and Hypertension, The Children's Memorial Health Institute, Warsaw, \\ Poland
}

\section{ABSTRACT}

Aim of the study: Response to corticosteroids is a major factor determining the final outcome of nephrotic syndrome (NS) in children. There is no consensus in terms of specific biomarkers of steroid sensitivity. There are reports on the value of urine neutrophil gelatinase-associated lipocalin (UNGAL) as a marker of steroid sensitivity, although this has not been definitively established. Objectives: To evaluate serum (s) and urine (u) NGAL concentrations as markers of response to steroid therapy.

Material and methods: This was a retrospective study including 43 patients (1-17 years old) divided into two groups as follows: 1) children with steroid-resistant nephrotic syndrome (SRNS, $n=14$ ) treated with additional immunosuppressive drugs, including cyclosporine A (CsA) and/or mycophenolate mofetil (MMF); and 2) steroid-sensitive nephrotic syndrome (SSNS, $n=29$ ). The control group consisted of age-matched healthy children (HC, $n=59)$.

Results: Median sNGAL concentration was higher in nephrotic patients $(83.0,43.8-351 \mathrm{ng} / \mathrm{ml})$ compared to HC $(51.4,12.1-193 \mathrm{ng} / \mathrm{ml} ; p=0.00)$. There was no difference in the sNGAL level between SRNS and SSNS patients $(p=0.34)$. Median uNGAL level was higher in the SRNS patients, compared to that in the SSNS group, although the difference was not significant $(2.71 \mathrm{ng} / \mathrm{ml}$, range: $0.02-62.8 \mathrm{ng} / \mathrm{ml}$ and $1.17 \mathrm{ng} / \mathrm{ml}$, range: $0.02-99.3 \mathrm{ng} / \mathrm{ml}$, respectively; $p=0.26$ ). Median sNGAL was higher in children treated with triple-drug regimens including cyclosporine A (CsA) $(82.6,68.6-351 \mathrm{ng} / \mathrm{ml})$ compared to the patients on double-drug regimen including mycophenolate mofetil (MMF) $(p=0.03)$. There was no correlation between sNGAL and CsA dose/blood concentration ratio. We found a negative correlation between SNGAL and renal function, reflected by the eGFR $(r=-0.41, p=0.01)$.

Conclusions: sNGAL concentration did not differ between steroid-resistant and steroid-sensitive nephrotic syndrome patients. The higher sNGAL concentration in patients on triple therapy (cyclosporine A + mycophenolate mofetil + prednisone $-\mathrm{CsA}+\mathrm{MMF}+\mathrm{PRED}$ ) reflects inferior renal function in patients with the most severe clinical course of NS.

KEY WORDS:

children, biomarkers, nephrotic syndrome, neutrophil gelatinase-associated lipocalin.

\section{ADDRESS FOR CORRESPONDENCE:}

Agnieszka Ochocińska, Department of Biochemistry, Radioimmunology, and Experimental Medicine, The Children's Memorial Health Institute, 20 Dzieci Polskich Ave., 04-730 Warsaw, Poland,

e-mail: a.ochocinska@ipczd.pl 


\section{INTRODUCTION}

Nephrotic syndrome (NS) is glomerular disease characterised by heavy proteinuria, hypoalbuminaemia, hyperlipidaemia, and oedema. Corticosteroid therapy is the primary and first-line treatment of nephrotic syndrome in children, and response to the steroids determines the final outcome. Prednisone (PRED) is primarily used in clinical practice. Patients who do not respond to fourweek therapy are considered as steroid resistant and, if the further alternative treatment also fails, they are at high risk of progression to the end-stage renal disease [1-3]. Second-line therapy in steroid-resistant NS includes drugs of different mechanisms of action such as calcineurin inhibitors (CNIs): cyclosporine A (CsA), tacrolimus (TAC), or mycophenolate mofetil (MMF) [3]. These drugs are administrated in double (PRED + CsA or PRED + MMF) or (if this therapy fails) in triple regimens (PRED + MMF + CsA).

Traditional markers used to evaluate and to monitor response to steroid treatment include proteinuria or serum albumin concentration; however, there is ongoing research aiming to define and validate other biomarkers [1, 4-9].

Neutrophil gelatinase-associated lipocalin (NGAL, lipocalin-2) is a $25 \mathrm{kDa}$ secretory protein secreted by neutrophils, macrophages, epithelial cells, hepatocytes, adipocytes, neurons, vascular smooth muscle cells, and neoplastic cells. It belongs to the family of lipocalins. Its main role is the transport of small molecules such as lipids and steroids [10]. There are numerous data on the important role of NGAL in the pathogenesis of acute kidney injury (AKI), diabetes, cardiovascular diseases, and cancer $[10,11]$. We previously showed that serum NGAL concentration is significantly elevated in children with inflammatory bowel disease [12]. Several studies confirmed the value of urine NGAL as a marker of acute kidney injury because it is rapidly released, even faster than creatinine, by the renal tubules, especially during renal injury $[2,5,10,13]$. Secretion of NGAL is localised in the distal convoluted tubule and the collecting duct while the proximal tubule is involved in NGAL reabsorption. Wasilewska et al. reported that both serum and urine NGAL concentration increase during CsA treatment of NS children [2]. We aimed to evaluate serum and urine NGAL concentration in nephrotic syndrome patients treated with steroids alone or with the combination of steroids and second-line drugs including CsA or MMF.

\section{MATERIAL AND METHODS}

Forty-three patients ( 16 boys and 27 girls) aged from 1 to 17 years (median: 9 years) with idiopathic nephrotic syndrome (INS), diagnosed and treated in the Department of Nephrology, Kidney Transplantation, and Hy- pertension of The Children's Memorial Health Institute, Warsaw, between November 2014 and July 2016, were enrolled in this retrospective, cross-sectional study. Thirteen of these children underwent kidney biopsy, with revealed five cases of minimal change disease (MCD), two cases of focal segmental glomerulosclerosis (FSGS), and six cases of mesangial proliferative glomerulonephritis (MPGN). All the patients were Caucasians. The patients were divided into two groups: children with steroid-resistant nephrotic syndrome (SRNS, $n=14$ ) and those with steroid-sensitive nephrotic syndrome (SSNS, $n=29$ ). The mean age of patients at the time of diagnosis was four years. The control group (HC, $n=59)$ included healthy children ( 26 boys and 33 girls aged from 1 to 14 years, median: 3 years) without history of renal disease, hypertension, diabetes, and metabolic and growth disorders. In these children UNGAL was not measured because collection of the urine samples was not possible at this time.

The protocol of this study was approved by the Hospital Ethics Committee. Informed consent was obtained from all relevant participants and their parents.

Quantification of the NGAL level was performed in the serum and urine samples using the NGAL ELISA Kit (BioVendor, Brno, Czech Republic) according to the manufacturer's instruction. The sensitivity of the assay was $0.02 \mathrm{ng} / \mathrm{ml}$. Intra- and inter-assay coefficients of variation (CV) were $7.7 \%$ and $9.8 \%$, respectively. Data were analysed both as raw and as normalised to the urine creatinine. The urine creatinine level was determined using a Jaffe's method (Beckman Creatinine Analyzer 2). Other biochemical parameters were determined using standard laboratory techniques. Serum creatinine was transformed to eGFR by the modified Schwartz formula [14].

Statistical analyses were performed using Statistica v.10.0 software (StatSoft, Inc., Tulsa, United States). Numerical data are expressed as median and range. Mean age was expressed in full years. Non-parametric tests were chosen because the groups were small or had non-normal distribution according to the Shapiro-Wilk test for normality. Groups were compared using Mann-Whitney $\mathrm{U}$ test, with $p$-values less than 0.05 considered significant. Correlation between the independent parameters was evaluated using Spearman's rank correlation test.

\section{RESULTS}

The median serum (s) NGAL level was higher in NS patients (83.0, range: $43.8-351 \mathrm{ng} / \mathrm{ml}$ ) compared to that in the HCs (51.4, range: $12.1-193 \mathrm{ng} / \mathrm{ml}$ ), $p=0.00$ (Fig. 1). Median SNGAL was significantly higher both in the SRNS (103, range: $50.2-351 \mathrm{ng} / \mathrm{ml}$ ) and SSNS (80.1, range: 43.8$163 \mathrm{ng} / \mathrm{ml}$ ) patients, respectively, compared to that in the HCs $(p=0.00$ and $p=0.00)$. However, there was no significant difference of sNGAL concentration between SRNS and SSNS group (103, range: $50.2-351 \mathrm{ng} / \mathrm{ml}$ and 80.1 , range: $43.8-163 \mathrm{ng} / \mathrm{ml} ; p=0.34)$. There was no dif- 
ference in the sNGAL concentration between SRNS and SSNS in regard to the gender of patients (boys: 111, range: 50.2-351 $\mathrm{ng} / \mathrm{ml}$ and 81.8 , range: $50.7-163 \mathrm{ng} / \mathrm{ml} ; p=0.47$, girls: 101 , range: $53.9-212 \mathrm{ng} / \mathrm{ml}$ and 74.3 , range: $43.8-$ $126 \mathrm{ng} / \mathrm{ml} ; p=0.37)$. The median value of uNGAL level was higher in SRNS patients compared to that in the SSNS group. The difference was not significant (2.71, range: $0.02-62.8 \mathrm{ng} / \mathrm{ml}$ and 1.17 , range: $0.02-99.3 \mathrm{ng} / \mathrm{ml}$, respectively; $p=0.26$ ). The results did not change when the values of uNGAL were adjusted for the urine creatinine concentration, $(2.38 \mathrm{ng} / \mathrm{mgCr}$ for SRNS vs. $1.10 \mathrm{ng} / \mathrm{mgCr}$ for SSNS children, respectively; $p=0.21$ ). The median value of the uNGAL concentration was higher in girls than in boys in the whole group $(2.96 \mathrm{ng} / \mathrm{ml}$ and $0.99 \mathrm{ng} / \mathrm{ml}$, $p=0.36$ ); however, the difference was not significant. In the SRNS group the median value of uNGAL concentration was much higher $(8.42 \mathrm{ng} / \mathrm{ml}$ and $1.57 \mathrm{ng} / \mathrm{ml}$ for girls and boys, respectively) although it was not significantly different either $(p=0.26)$ (Table 1).

Analysis of correlation between sNGAL concentration and selected renal parameters (Table 2) showed statistically significant, positive correlation of lipocalin-2 with creatinine concentration $(r=0.45, p=0.00)$ and negative correlation with the eGFR value, respectively $(r=-0.41$, $p=0.00)$. No correlation was found between sNGAL and uNGAL as well as between the serum albumin concentration and degree of proteinuria.

The concentration of UNGAL in patients in remission and during relapse of NS was also evaluated. We separately evaluated two subgroups: children with $\mathrm{uPCR}<2 \mathrm{mg} / \mathrm{mg}$

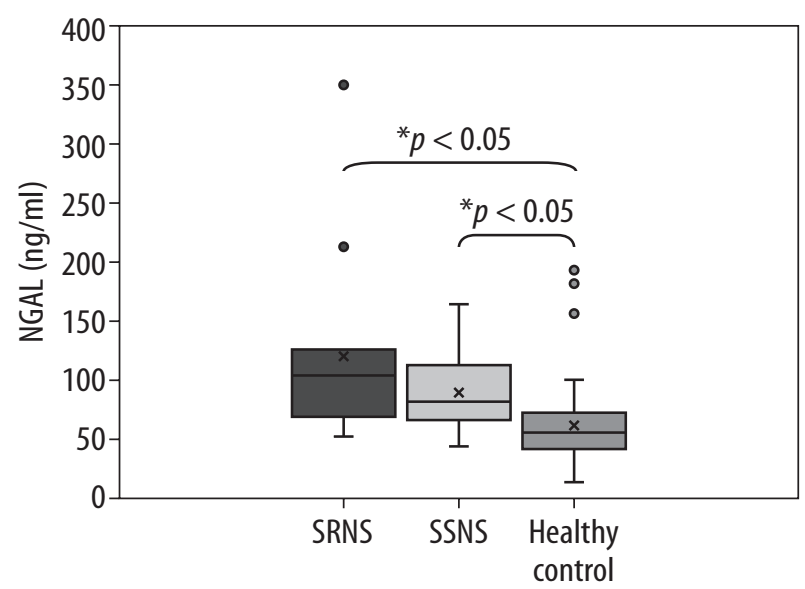

FIGURE 1. NGAL concentrations in children with nephrotic syndrome and in healthy control

(classified as partial remission) and children with uPCR $\geq 2 \mathrm{mg} / \mathrm{mg}$ (classified as relapse). Median uNGAL concentration was higher in SRNS and SSNS patients in relapse (3.43 ng/ml and $1.32 \mathrm{ng} / \mathrm{ml}$, respectively) compared that in the SRNS and SSNS patients in remission $(1.57 \mathrm{ng} / \mathrm{ml}$ and $0.47 \mathrm{ng} / \mathrm{ml}$, respectively); these differences were not significant ( $p=0.75, p=0.85$, respectively) (Table 3 ).

Additional analysis was made regarding the therapeutic regimen (Table 4). Median values of uNGAL and sNGAL concentration were higher in patients receiving calcineurin inhibitors (CsA or TAC) in double or triple regimens; however, the only significant difference was seen in the sNGAL level in the subgroup receiving triple

TABLE 1. NGAL concentrations in children with nephrotic syndrome and in healthy control

\begin{tabular}{|c|c|c|c|c|c|c|c|c|}
\hline \multirow[t]{2}{*}{ Group } & \multirow[t]{2}{*}{$n$} & \multirow{2}{*}{$\begin{array}{l}\text { Age } \\
\text { (yrs) }\end{array}$} & \multicolumn{2}{|c|}{ Serum NGAL ${ }^{1}$ (ng/ml) } & \multicolumn{2}{|c|}{ Urine $\mathrm{NGAL}^{2}(\mathrm{ng} / \mathrm{ml})$} & \multicolumn{2}{|c|}{ Urine $\mathrm{NGAL} / \mathrm{Cr}^{3}$ (ng/mg $\mathrm{Cr}$ ) } \\
\hline & & & median & range & median & range & median & range \\
\hline$N S^{a}$ & 43 & $9 \pm 5$ & 83.0 & $43.8-351$ & 1.45 & $0.02-99.3$ & 1.68 & $0.01-88.5$ \\
\hline boys $^{\text {b }}$ & 27 & $9 \pm 5$ & 84.6 & $50.2-351$ & 0.99 & $0.02-99.3$ & 0.93 & $0.01-76.4$ \\
\hline girlsc & 16 & $9 \pm 5$ & 78.8 & $43.8-212$ & 2.96 & $0.02-62.8$ & 3.90 & $0.02-88.5$ \\
\hline SRNS $^{\mathrm{d}}$ & 14 & $9 \pm 6$ & 103 & $50.2-351$ & 2.71 & $0.02-62.8$ & 2.38 & $0.03-88.5$ \\
\hline boys $^{e}$ & 7 & $9 \pm 7$ & 111 & $50.2-351$ & 1.57 & $0.02-7.15$ & 1.73 & $0.03-2.52$ \\
\hline girls ${ }^{f}$ & 7 & $9 \pm 6$ & 101 & $53.9-212$ & 8.42 & $0.02-62.8$ & 9.06 & $0.04-88.5$ \\
\hline SSNS $^{g}$ & 29 & $9 \pm 5$ & 80.1 & $43.8-163$ & 1.17 & $0.02-99.3$ & 1.10 & $0.01-76.4$ \\
\hline boys $^{h}$ & 20 & $9 \pm 5$ & 81.8 & $50.7-163$ & 0.47 & $0.02-99.3$ & 0.59 & $0.01-76.4$ \\
\hline girlsi & 9 & $9 \pm 4$ & 74.3 & $43.8-126$ & 1.68 & $0.02-13.6$ & 1.87 & $0.02-6.71$ \\
\hline$H C^{j}$ & 59 & $4 \pm 3$ & 51.4 & $12.1-193$ & ND & ND & ND & ND \\
\hline boys $^{k}$ & 26 & $3 \pm 3$ & 58.4 & 18.7-182 & ND & ND & ND & ND \\
\hline girls' & 33 & $4 \pm 3$ & 52.1 & $12.1-193$ & ND & ND & ND & ND \\
\hline
\end{tabular}

$1 a$ vs. $1 \mathrm{~b} p=0.66,1 \mathrm{a}$ vs. $1 \mathrm{c} p=0.53,1 \mathrm{a}$ vs. $1 \mathrm{~d} p=0.49,1 \mathrm{a}$ vs. $1 \mathrm{~g} p=0.67,1 \mathrm{a}$ vs. $1 \mathrm{j} p=0.00,1 \mathrm{~b}$ vs. $1 \mathrm{c} p=0.36,1 \mathrm{~b}$ vs. $1 \mathrm{e} p=0.58,1 \mathrm{~b}$ vs. $1 \mathrm{~h} p=0.78,1 \mathrm{~b}$ vs. $1 \mathrm{k} p=0.00,1 \mathrm{c}$ vs. $1 \mathrm{f} p=0.57,1 \mathrm{c} \mathrm{vs}$.

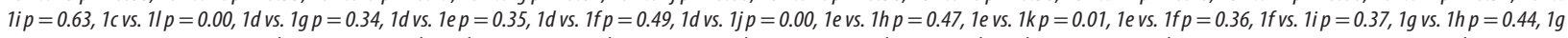
vs. $1 \mathrm{i} p=0.38,1 \mathrm{~g}$ vs. $1 \mathrm{j} p=0.00,1 \mathrm{~h}$ vs. $1 \mathrm{i} p=0.40,1 \mathrm{~h}$ vs. $1 \mathrm{k} p=0.00,1 \mathrm{i}$ vs. $11 \mathrm{p}=0.03,1 \mathrm{j}$ vs. $1 \mathrm{k} p=0.80,1 \mathrm{j}$ vs. $11 \mathrm{l} p=0.86,1 \mathrm{kvs} .11 \mathrm{p}=0.68,2 \mathrm{avs} .2 \mathrm{bp}=0.48,2 \mathrm{v}$ vs. $2 \mathrm{c} p=0.35,2 \mathrm{avs} .2 \mathrm{~d} p=0.40,2 \mathrm{a}$

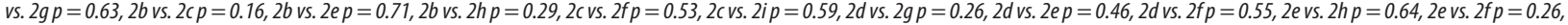
$2 f v s .2 i p=0.31,2 g$ vs. $2 h p=0.72,2 g$ vs. $2 i p=0.56,2 h$ vs. $2 i p=0.42,3 a$ vs. $3 b p=0.45,3 a v s .3 c p=0.33,3 a v s .3 d p=0.36,3 a v s .3 g p=0.60,3 b v s .3 c p=0.14,3 b v s .3 e p=0.71,3 b v s .3 h p=0.87$,

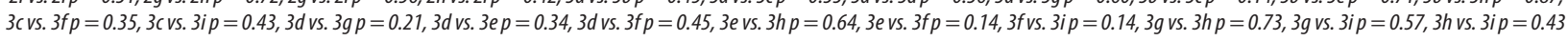
NGAL - neutrophil gelatinase-associated lipocalin, Cr - serum creatinine, NS - nephrotic syndrome, SRNS - steroid-resistant nephrotic syndrome, SSNS - steroid-sensitive nephrotic syndrome, HC - healthy control, ND - not determined 
TABLE 2. Correlation of the NGAL level with biochemical parameters in children with nephrotic syndrome

\begin{tabular}{|c|c|c|c|c|c|}
\hline & & $n$ & Serum NGAL (ng/ml) & Urine NGAL (ng/ml) & Urine NGAL/Cr (ng/mg Cr) \\
\hline \multirow[t]{3}{*}{ GFR } & NS & 43 & $\begin{array}{c}-0.41^{*} \\
p=0.01\end{array}$ & $\begin{array}{c}-0.07 \\
p=0.68\end{array}$ & $\begin{array}{c}0.03 \\
p=0.86\end{array}$ \\
\hline & SRNS & 14 & $\begin{array}{c}-0.45 \\
p=0.10\end{array}$ & $\begin{array}{c}0.43 \\
p=0.16\end{array}$ & $\begin{array}{c}0.42 \\
p=0.17\end{array}$ \\
\hline & SSNS & 29 & $\begin{array}{c}-0.32 \\
p=0.09\end{array}$ & $\begin{array}{c}-0.10 \\
p=0.61\end{array}$ & $\begin{array}{c}0.06 \\
p=0.77\end{array}$ \\
\hline \multirow[t]{3}{*}{ ALBUMIN } & $\mathrm{N}$ & 43 & $\begin{array}{c}-0.08 \\
p=0.60\end{array}$ & $\begin{array}{c}0.11 \\
p=0.50\end{array}$ & $\begin{array}{c}0.05 \\
p=0.74\end{array}$ \\
\hline & SRNS & 14 & $\begin{array}{c}0.06 \\
p=0.83\end{array}$ & $\begin{array}{c}0.17 \\
p=0.60\end{array}$ & $\begin{array}{c}0.16 \\
p=0.62\end{array}$ \\
\hline & SSNS & 29 & $\begin{array}{c}-0.21 \\
p=0.29\end{array}$ & $\begin{array}{c}0.01 \\
p=0.94\end{array}$ & $\begin{array}{c}-0.06 \\
p=0.77\end{array}$ \\
\hline \multirow[t]{3}{*}{ CREATININE } & NS & 43 & $\begin{array}{c}0.45^{*} \\
p=0.00\end{array}$ & $\begin{array}{c}0.10 \\
p=0.54\end{array}$ & ND \\
\hline & SRNS & 14 & $\begin{array}{c}0.53 \\
p=0.05\end{array}$ & $\begin{array}{c}-0.52 \\
p=0.08\end{array}$ & ND \\
\hline & SSNS & 29 & $\begin{array}{c}0.39 \\
p=0.06\end{array}$ & $\begin{array}{c}0.21 \\
p=0.28\end{array}$ & ND \\
\hline \multirow[t]{3}{*}{ uPCR } & NS & 43 & $\begin{array}{c}-0.11 \\
p=0.54\end{array}$ & $\begin{array}{c}0.32 \\
p=0.80\end{array}$ & $\begin{array}{c}0.00 \\
p=1.00\end{array}$ \\
\hline & SRNS & 14 & $\begin{array}{c}-0.12 \\
p=0.70\end{array}$ & $\begin{array}{c}-0.09 \\
p=0.79\end{array}$ & $\begin{array}{c}-0.16 \\
p=0.63\end{array}$ \\
\hline & SSNS & 29 & $\begin{array}{c}-0.20 \\
p=0.39\end{array}$ & $\begin{array}{c}0.14 \\
p=0.57\end{array}$ & $\begin{array}{c}0.11 \\
p=0.63\end{array}$ \\
\hline \multirow[t]{3}{*}{$\mathrm{uPCR}<2$} & NS & 22 & $\begin{array}{c}-0.42 \\
p=0.19\end{array}$ & $\begin{array}{c}-0.41 \\
p=0.21\end{array}$ & $\begin{array}{c}-0.31 \\
p=0.36\end{array}$ \\
\hline & SRNS & 6 & $\begin{array}{c}-0.21 \\
p=0.79\end{array}$ & $\begin{array}{c}-0.74 \\
p=0.26\end{array}$ & $\begin{array}{c}-0.60 \\
p=0.40\end{array}$ \\
\hline & SSNS & 16 & $\begin{array}{c}-0.67 \\
p=0.10\end{array}$ & $\begin{array}{c}-0.10 \\
p=0.83\end{array}$ & $\begin{array}{c}-0.10 \\
p=0.83\end{array}$ \\
\hline \multirow[t]{3}{*}{$\mathrm{uPCR} \geq 2$} & NS & 21 & $\begin{array}{c}0.11 \\
p=0.62\end{array}$ & $\begin{array}{c}0.17 \\
p=0.48\end{array}$ & $\begin{array}{c}0.09 \\
p=0.71\end{array}$ \\
\hline & SRNS & 8 & $\begin{array}{c}0.17 \\
p=0.69\end{array}$ & $\begin{array}{c}-0.07 \\
p=0.88\end{array}$ & $\begin{array}{c}-0.18 \\
p=0.70\end{array}$ \\
\hline & SSNS & 13 & $\begin{array}{c}-0.13 \\
p=0.67\end{array}$ & $\begin{array}{c}0.35 \\
p=0.24\end{array}$ & $\begin{array}{c}0.31 \\
p=0.31\end{array}$ \\
\hline
\end{tabular}

NGAL - neutrophil gelatinase-associated lipocalin, Cr - serum creatinine, uPCR - urine protein : creatinine ratio, NS - nephrotic syndrome, SRNS - steroid-resistant nephrotic syndrome, SSNS - steroid-sensitive nephrotic syndrome, $N D$ - not determined

therapy (CsA + MMF + PRED) in comparison to the double (MMF + PRED) therapy (82.6, range: $68.6-351 \mathrm{ng} / \mathrm{ml}$ and 65.8 , range: $43.8-83.3 \mathrm{ng} / \mathrm{ml} ; p=0.03)$ We analysed correlations between dose/blood concentration index of cyclosporine A and sNGAL, and there was no significant association $(r=0.12, p=0.66$ and $r=0.26, p=0.71$, respectively). We have found that renal function (expressed as serum creatinine levels) was highest in the patients on triple therapy (median 0.60, range: $0.30-0.96 \mathrm{ng} / \mathrm{ml}$, $p=0.04$ and $p=0.02$ ) compared to patients on CsA + PRED or MMF + PRED therapy. The highest sNGAL levels in this subgroup may reflect inferior renal function.

\section{DISCUSSION}

The results of our study did not exhibit significant changes of the serum and urine NGAL concentration in response to steroid therapy in nephrotic syndrome children. Our results confirmed published data regarding the correlation between NGAL and renal function [2, 15, 16].

Moreover, our study did not confirm the observation of Nickavar et al. [13] that the ratio of urine NGAL to creatinine concentration is a better index of steroid response than the urine NGAL concentration alone. A report by Delanaye et al. suggested also that the correction of urine 
TABLE 3. NGAL concentration in children with partial remission and relapse

\begin{tabular}{|c|c|c|c|c|c|c|c|c|}
\hline & & \multirow[t]{2}{*}{$n$} & \multicolumn{2}{|c|}{ Serum NGAL ${ }^{1}(\mathrm{ng} / \mathrm{ml})$} & \multicolumn{2}{|c|}{ Urine NGAL ${ }^{2}$ (ng/ml) } & \multicolumn{2}{|c|}{ Urine NGAL/ $\mathrm{Cr}^{3}$ (ng/mg $\mathrm{Cr}$ ) } \\
\hline & & & median & range & median & range & median & range \\
\hline \multirow{3}{*}{$\begin{array}{l}\text { uPCR }<2 \\
\text { (partial } \\
\text { remission) }\end{array}$} & $N S^{a}$ & 22 & 93.8 & $43.8-351$ & 0.74 & $0.02-99.3$ & 0.77 & $0.01-88.5$ \\
\hline & SRNS $^{b}$ & 6 & 111 & $81.7-351$ & 1.57 & $0.02-62.8$ & 1.62 & $0.02-88.5$ \\
\hline & SSNSC & 16 & 81.8 & $43.8-163$ & 0.47 & $0.02-99.3$ & 0.59 & $0.01-76.4$ \\
\hline \multirow{3}{*}{$\begin{array}{l}\mathrm{uPCR} \geq 2 \\
\text { (relapse) }\end{array}$} & $N S^{d}$ & 21 & 75.8 & $50.2-212$ & 1.83 & $0.02-25.2$ & 1.82 & $0.02-23.4$ \\
\hline & SRNS & 8 & 84.9 & $50.2-212$ & 3.43 & $0.02-25.2$ & 2.52 & $0.04-23.4$ \\
\hline & SSNS ${ }^{f}$ & 13 & 75.8 & $50.7-133$ & 1.32 & $0.02-13.6$ & 1.26 & $0.02-14.5$ \\
\hline
\end{tabular}

16 vs. 1 e $p=0.85,1$ c vs. $1 f p=0.46,2 b$ vs. $2 e p=0.75,2$ cvs. $2 f p=0.85,3 b$ vs. $3 e p=0.63,3$ c vs. $3 f p=0.85$

NGAL - neutrophil gelatinase-associated lipocalin, Cr - serum creatinine, uPCR - urine protein:creatinine ratio, NS - nephrotic syndrome, SRNS - steroid-resistant nephrotic syndrome, SSNS - steroid-sensitive nephrotic syndrome

TABLE 4. NGAL concentration in patients depending on treatment

\begin{tabular}{|c|c|c|c|c|c|c|c|}
\hline & \multirow[t]{2}{*}{$n$} & \multicolumn{2}{|c|}{ Serum NGAL ${ }^{1}(\mathrm{ng} / \mathrm{ml})$} & \multicolumn{2}{|c|}{ Urine $\mathrm{NGAL}^{2}(\mathrm{ng} / \mathrm{ml})$} & \multicolumn{2}{|c|}{ Urine NGAL/Cr ${ }^{3}$ (ng/mg Cr) } \\
\hline & & median & range & median & range & median & range \\
\hline Pred + CsA + MMFa & 12 & 82.6 & $68.6-351$ & 1.32 & $0.02-99.3$ & 1.26 & $0.00-76.4$ \\
\hline Pred + CsA/TAC ${ }^{b}$ & 13 & 105 & $50.2-137$ & 1.45 & $0.02-62.8$ & 1.68 & $0.02-88.5$ \\
\hline Pred + MMFc & 6 & 65.8 & $43.8-83.3$ & 1.29 & $0.02-9.80$ & 3.07 & $0.02-6.71$ \\
\hline
\end{tabular}

1avs. $1 b p=0.74,1 a$ vs. $1 c p=0.03,1 b$ vs. $1 c p=0.10,2 a$ vs. $2 b p=1.00,2 a$ vs. $2 c p=0.88,2 b$ vs. $2 c p=0.88,3 a$ vs. $3 c p=0.95,3 a$ vs. $3 c p=0.73,3 b$ vs. $3 c p=0.88$

$N G A L$ - neutrophil gelatinase-associated lipocalin, $C r$ - serum creatinine, Pred - prednisolone, CsA - cyclosporine, MMF-mycophenolate mofetil, TAC - tacrolimus

NGAL concentration to urinary creatinine level reduces the variability of the uNGAL values [15]. We could not confirm that it improves the usefulness of NGAL concentration to reflect the steroid-responsiveness of NS because both parameters (unadjusted and creatinine-adjusted values of the uNGAL) were not significant in this term.

The numerical differences in overall NGAL concentration between our and other results could be caused, at least in a part, by the use of different antibodies in immunoassays, and different sensitivity, specificity, and precision of the commercially available diagnostic tests. NGAL is a heterogeneous protein and may exist as a $25 \mathrm{kDa}$ monomer, $45 \mathrm{kDa}$ homodimer, and $135 \mathrm{kDa}$ heterodimer consisting of a monomer covalently bound with neutrophil gelatinase (MMP-9). Neutrophils synthesise the monomer and homodimer while the renal tubular epithelial cells can synthesise the monomer and heterodimer. Therefore, only these assays that specifically detect molecular forms of NGAL will allow assessment of the origin of NGAL and be able to distinguish the NGAL induced by the cell "stress" (infection, inflammation, and ischaemia) from proximal injury-induced NGAL excretion. Unfortunately, the "cocktail" of antibodies used in the currently available immunoassays does not distinguish between various molecular forms of NGAL and does not allow the unambiguous determination of the protein source. Moreover, in the biological material from patients with different pathological conditions there may be present various substances interfering in immunoassays (matrix effect) $[7,10]$.

The possible reason of higher concentration of NGAL in serum and urine of patients with SRNS or SSNS may be related to local renal effect of calcineurin inhibitor [2, 17]. Our results confirm that serum and urinary NGAL concentration is increased significantly in patients treated with a combination of drugs that include calcineurin inhibitors in comparison to those treated with a non-nephrotoxic corticosteroid-sparing agent: mycophenolate mofetil. On the other hand, the patients with the highest concentration of sNGAL while on triple therapy exhibited the highest creatinine concentration and represented the most severe clinical subgroup; resistant to steroid monotherapy or double therapy. There was no correlation between sNGAL and dose or blood concentration of cyclosporine A. It is then possible that high sNGAL concentration reflects renal function deteriorated in the course of chronic glomerular disease but not the direct toxicity of the drug.

Non-invasive diagnostic tests aimed to predict the response to steroids are still under evaluation. Korzeniecka-Kozerska et al. suggested use of the urinary MMP-9/ NGAL ratio as a differentiation marker between MCD and FSGS. They demonstrated that the MMP-9/NGAL ratio may be increased in patients with FSGS [18]. Bennet 
et al. propose the application of a 10-biomarker panel to distinguish between SRNS and SSNS. According to the authors, this method is characterised by the excellent discriminatory power to identify SRNS $[4,19]$. Metabolomics research through the analysis of circulating metabolites of renal gluconeogenesis strengthens the hypothesis about the involvement of the proximal tubule in the pathology of SRNS. Very recent data suggest that proteomic analysis is capable of identifying candidate biomarkers of steroid resistance in paediatric nephrotic syndrome [7]. Further research is required to identify diagnostic markers using modern analytical techniques such as liquid chromatography-mass spectrometry (LC-MS) or gas chromatography-mass spectrometry (GC-MS) [20]. The results of our study confirm recent reports [10,19] suggesting that neutrophil gelatinase-associated lipocalin is not suitable as a single marker to detect, follow up and monitor the treatment response in paediatric nephrotic syndrome.

We are aware of the limitations of our study. It was a single-centre study with a limited group of patients, including children with a long-term history of the disease and therapy; therefore, the analysis was not free from confounding factors.

In conclusion: the concentration of NGAL in serum and urine did not reflect the response to steroid therapy in children with nephrotic syndrome. We presume that due to several confounding factors, suitability of NGAL evaluation may be limited to the early phase of the disease, probably to the first episodes of nephrotic syndrome and prospective assessment. "Late cases", treated for a long time with variable drug regimens, and evaluated retrospectively, will not profit from this test in clinical practice.

\section{ACKNOWLEDGEMENT}

This project was supported by the Ministry of Science and Higher Education (grant for young scientist no. M11/14.

\section{DISCLOSURE}

The authors declare no conflict of interest.

\section{REFERENCES}

1. Gheissari A, Rezaii Z, Merrikhi A, et al. Association of neutrophil gelatinase associated lipocalin and cystatin- $\mathrm{C}$ with kidney function in children with nephrotic syndrome. Int J Prev Med 2013; 4: 956963.

2. Wasilewska A, Zoch-Zwierz W, Taranta-Janusz K, et al. Neutrophil gelatinase-associated lipocalin (NGAL): a new marker of cyclosporine nephrotoxicity? Pediatr Nephrol 2010; 25: 889-897.

3. Kidney Disease: Improving Global Outcomes (KDIGO) Glomerulonephritis Work Group. KDIGO Clinical Practice Guideline for Glomerulonephritis. Kidney Int 2012; 2 (Suppl.): 139-274.
4. Bennett MR. Biomarkers of therapeutic response in primary nephrotic syndrome: response. Pediatr Nephrol 2013; 28: 161-162.

5. Bennett MR, Piyaphanee N, Czech K, et al. NGAL distinguishes steroid sensitivity in idiopathic nephrotic syndrome. Pediatr Nephrol 2012; 27: 807-812.

6. Chehade H, Parvex P, Poncet A, et al. Urinary low-molecular-weight protein excretion in pediatric idiopathic nephrotic syndrome. Pediatr Nephrol 2013; 28: 2299-2306.

7. Mucha K, Foroncewicz B, Pączek L. How to diagnose and follow patients with glomerulonephritis without kidney biopsy? Pol Arch Med Wewn 2016; 126: 471-473.

8. Serwin NM, Wiśniewska M, Jesionowska A, et al. Serum levels of 12 renal function and injury markers in patients with glomerulonephritis. Pol Arch Med Wewn 2016; 26: 483-493.

9. Trachtman H. Biomarkers of therapeutic response in primary nephrotic syndrome. Pediatr Nephrol 2013; 28: 159.

10. Noto A, Cibecchini F, Fanos V, et al. NGAL and Metabolomics: The Single Biomarker to Reveal the Metabolome Alterations in Kidney Injury. Biomed Res Int 2013; 2013: 612032.

11. Stejskal D, Karpisek M, Humenanska V, et al. Lipocalin-2: development, analytical characterization, and clinical testing of a new ELISA. Horm Metab Res 2008; 40: 381-385.

12. Janas RM, Ochocińska A, Snitko R, et al. Neutrophil gelatinase-associated lipocalin in blood in children with inflammatory bowel disease. J Gastroenterol Hepatol 2014; 29: 1883-1889.

13. Nickavar A, Safaeian B, Sadeghi-Bojd S, et al. Urine Neutrophil Gelatinase Associated Lipocalin to Creatinine Ratio: A Novel Index for Steroid Response in Idiopathic Nephrotic Syndrome. Indian J Pediatr 2016; 83: 18-21.

14. Schwartz GJ, Muñoz A, Schneider MF, et al. New equations to estimate GFR in children with CKD. J Am Soc Nephrol 2009; 20: 629-637.

15. Delanaye P, Rozet E, Krzesinski JM, et al. Urinary NGAL measurement: biological variation and ratio to creatinine Clin Chim Acta 2011; 412: 390 .

16. Waikar SS, Sabbisetti VS, Bonventre JV. Normalization of urinary biomarkers to creatinine during changes in glomerular filtration rate. Kidney Int 2010; 78: 486-494.

17. Gacka E, Życzkowski M, Bogacki R, et al. The Usefulness of Determining Neutrophil Gelatinase-Associated Lipocalin Concentration Excreted in the Urine in the Evaluation of Cyclosporine A Nephrotoxicity in Children with Nephrotic Syndrome. Dis Markers 2016; 2016: 6872149.

18. Korzeniecka-Kozerska A, Wasilewska A, Tenderenda E, et al. Urinary MMP-9/NGAL ratio as a potential marker of FSGS in nephrotic children. Dis Markers 2013; 34: 357-362.

19. Bennett MR, Pleasant L, Haffner Ch, et al. Novel Biomarker Panel to Identify Steroid Resistance in Childhood Idiopathic Nephrotic Syndrome. Biomark Insights 2017; 12: 1-11.

20. Lee JE, Lee YH, Kim SY, et al. Systematic biomarker discovery and coordinative validation for different primary nephrotic syndromes using gas chromatography-mass spectrometry. J Chromatogr A 2016; 1453: 105-115. 